\title{
Comparative analysis of single-phase self-excited induction generators of various rotor cages
}

\author{
Krzysztof Makowski $^{1} \cdot$ Aleksander Leicht ${ }^{1}$ (i)
}

Received: 25 March 2019 / Accepted: 5 August 2019 / Published online: 12 August 2019

(c) The Author(s) 2019

\begin{abstract}
The paper deals with a simulation study of influence of conductive material of the rotor squirrel cage on output characteristics of single-phase self-excited induction generators. For calculation of performance characteristics, two-dimensional field-circuit model of the single-phase induction generator was applied. A comparison of self-excitation waveforms of terminal voltage and load characteristics of the generators for rotor bars of the same shape, made of aluminium and copper, was presented. The obtained simulation results by the field-circuit model and analysis may be utilized for designing new constructions of single-phase self-excited induction generators as well for modifying construction of the generators designing on the base of general-purpose single-phase induction motors.
\end{abstract}

Keywords Rotor cage $\cdot$ Induction generators $\cdot$ Single-phase $\cdot$ Self-excitation $\cdot$ Performance characteristics

\section{Introduction}

For production of low-power single-phase electrical energy, self-excited induction generators (SP-SEIGs) driven by a micro-hydro or micro-wind turbine may be applied. Usually, for single-phase power generation as an auxiliary energy source at household, single phase of two separate stator windings' induction machines of power up to $3 \mathrm{~kW}$ will be sufficient operating as an autonomous single-phase selfexcited induction generator [1-6]. When larger electrical power is needed, a three-phase stator winding self-excited induction generator with single-phase output should be employed for feeding single-phase loads [7-9]. Theoretically, any induction machine designed for motor operation may be directly utilized as induction generator, but its performance will be not satisfactory since, for example, problems with self-excitation of the generator may be occurred and terminal voltage regulation as well as the maximum output power at desired speed of rotation will be not sufficient. To obtain satisfactory performance of the induction generator, some reconstruction of stator windings [3, 5],

Aleksander Leicht

aleksander.leicht@pwr.edu.pl

$1 \quad$ Faculty of Electrical Engineering, Wroclaw University of Science and Technology, Wybrzeze Wyspianskiego Str. 27, 50-370 Wroclaw, Poland rotor cage and magnetic core are necessary to improve the performance characteristics of the generator. Multiple papers have been reported on the use of copper squirrel rotor cage in induction motors [10-12], but only a few dealt with induction machines operating as self-excited induction generators $[13,14]$. Boglietti et al. [10] compared three-phase induction motors with aluminium and copper rotor cage in terms of efficiency. The presented results show that the replacement of the aluminium cage by copper one increases the motor's rated efficiency, while the influence on motor currents and torque was not significant. The paper [11] presents the construction details of welded and die-cast rotor cages made of aluminium and copper and compares four designs in terms of efficiency and manufacturing costs. The authors in [12] presented the comparison of performance characteristics of induction motors with aluminium and copper rotor cages as well as for a double-cage copper rotor. Application of the copper cage resulted in increasing motor efficiency and the starting torque. The paper [13] presented a qualitative performance analysis of aluminium and copper rotor three-phase self-excited induction generator and was mostly devoted to circuit modelling. The $d q$ model of an induction generator was expanded to include skin effect and temperature. The investigations showed that the voltage build-up time in the case of copper rotor is longer when compared with the aluminium rotor machine. Tudorache et al. [14] compared a three-phase induction machine with aluminium 
and copper cages, operating as motor and generator. Application of a copper cage resulted in increase in efficiency by $2.3 \%$ for motoring mode and by $1.8 \%$ for generator operation. Lowering of staring torque for motor was compensated by redesign of rotor slot shape and application of doublecage rotor.

The paper presents the qualitative investigation on utilizing copper as conductive material in rotor squirrel cage (i.e. for bars and rings) of single-phase self-excited induction generators instead of aluminium which is commonly used in general-purpose single-phase capacitor induction motors. Taking into account previously conducted study by the authors in [4], only three shapes of rotor bars, i.e. rounded trapezoidal, rectangular and round, have been considered in this paper for two different conductive materials.

\section{Copper versus aluminium rotor cage design of the generator}

Self-excitation waveforms and load characteristics of the SPSEIG were computed for various shapes of squirrel cage rotor bars on the base of machine of aluminium rotor cage with rounded trapezoidal bars. The half-section of twodimensional field-circuit model of the single-phase selfexcited induction generator is shown in Fig. 1. In searching of better performance of the generator under load, the following modifications of the construction have been proposed: the squirrel rotor cage of the generator made of copper instead of aluminium and three various rotor bar shapes were taken into consideration. The dimensions of round and rectangular rotor bars were determined so as to maintain the tooth width close to the tooth width of the base model at the narrowest point.

\section{Field-circuit method of computation of performance characteristics of the SP-SEIGs}

A single-phase four-pole induction generator was modelled by using Flux2D software package. The machine was originally designed for motor operation, with rated voltage of $230 \mathrm{~V}$ and rated power of $1.1 \mathrm{~kW}$. The original rotor squirrel cage has 30 aluminium bars of rounded trapezoidal shape. In terms of geometrical symmetry and electromagnetic periodicity of the machine, two-dimensional domain of magnetic field computation was reduced to two pole pitches of the cross section of the generator by application of cyclic boundary conditions. Dirichlet boundary conditions for magnetic vector potential were imposed on the outer edge of the stator core and the inner edge of the rotor core. The modelled 2D finite element mesh of the generator presented in Fig. 1 consists of triangular and quadrilateral elements and about 22,000 nodes. The cross-sectional geometry of the generator in Fig. 1 represents the generator with rounded trapezoidal rotor bars. For remaining shapes of the rotor bars, the rotor geometry has been modified, and the finite element mesh was accordingly updated. FE meshes for different slot regions of various bar shapes are presented enlarged in Fig. 2.

Applying magnetic vector potential formulations, the 2D magnetic field in the induction generator may be determined by the equation:

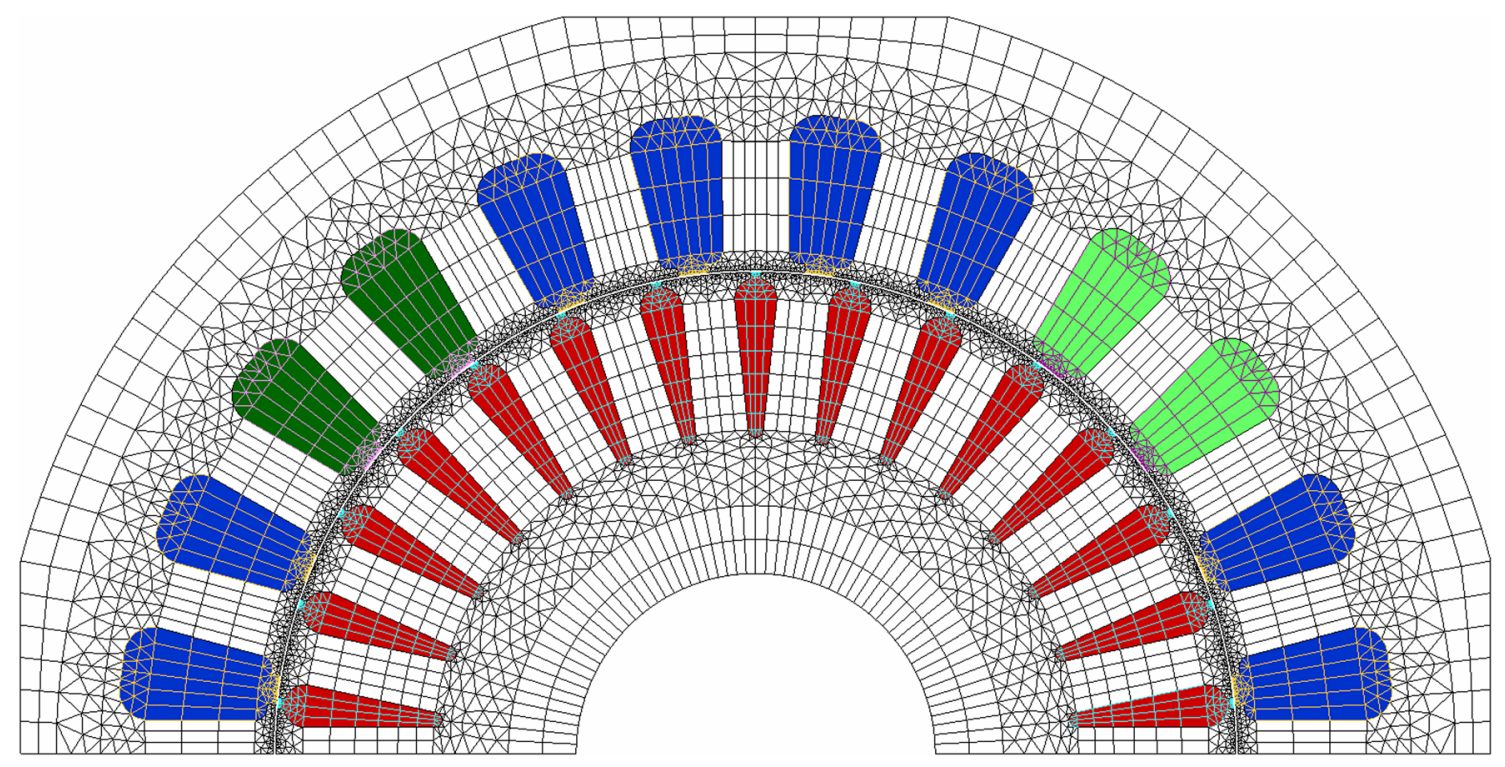

Fig. 1 FE mesh of 2D field-circuit model of the single-phase induction generator 


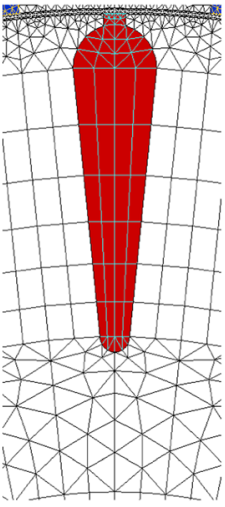

(a)

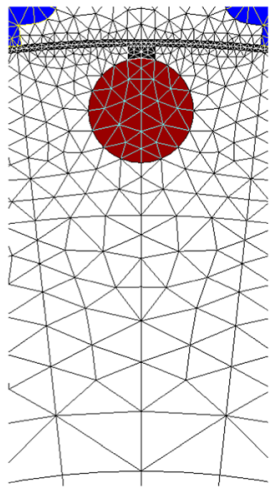

(b)

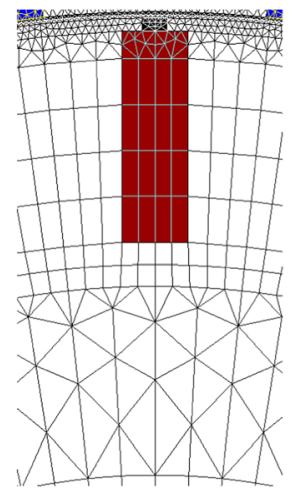

(c)
Fig. 2 Shapes of rotor bars: a rounded trapezoidal, $\mathbf{b}$ round, $\mathbf{c}$ rectangular

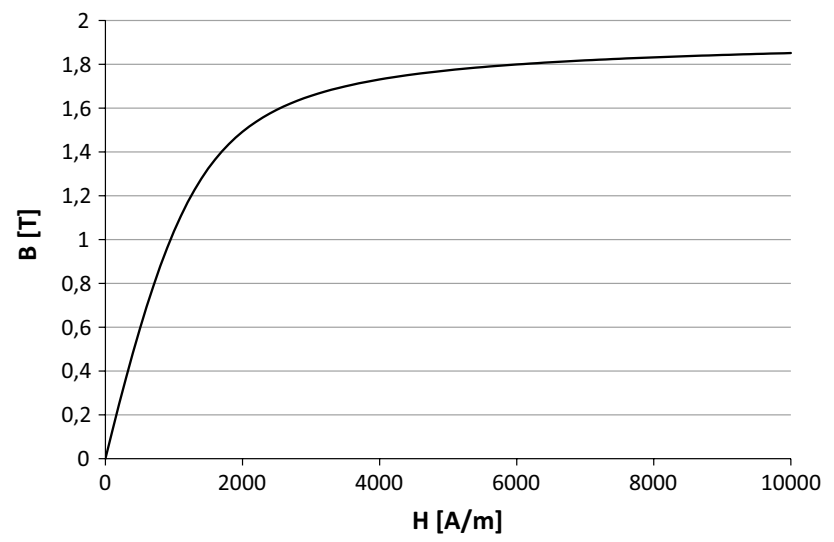

Fig. 3 Magnetization characteristic of iron core of tested induction machine

$\operatorname{curl}(v \cdot \operatorname{curl} \boldsymbol{A})= \begin{cases}\boldsymbol{J}_{s} & \text { in stator windings } \\ \boldsymbol{J}_{\boldsymbol{b}}-\sigma \cdot \frac{\partial \boldsymbol{A}}{\partial t} & \text { in rotor bars } \\ 0 & \text { in air, iron core and shaft }\end{cases}$

where $\mathbf{A}[0,0, A(x, y, t)]$ is the magnetic vector potential, $\mathbf{J}_{\mathbf{s}}\left[0,0, J_{s}(x, y, t)\right], \mathbf{J}_{\mathbf{b}}\left[0,0, J_{b}(x, y, t)\right]$-the current density in the stator slots and rotor bars, $\nu$-reluctivity of magnetic material, $\sigma$-electric conductivity of winding conductors. The field equations are coupled with voltage equations of stator windings and rotor cage and are solved simultaneously to obtain voltages and currents induced in the stator and rotor. Having the variables $\mathbf{A}, \mathbf{J}_{\mathbf{s}}$ and $\mathbf{J}_{\mathbf{b}}$ computed, the other quantities of electromagnetic field as magnetic flux, flux density in whole cross section of the machine, etc., can be determined taking into account the nonlinear magnetization characteristic of iron-laminated core of the tested singlephase induction machine shown in Fig. 3. The magnetizing

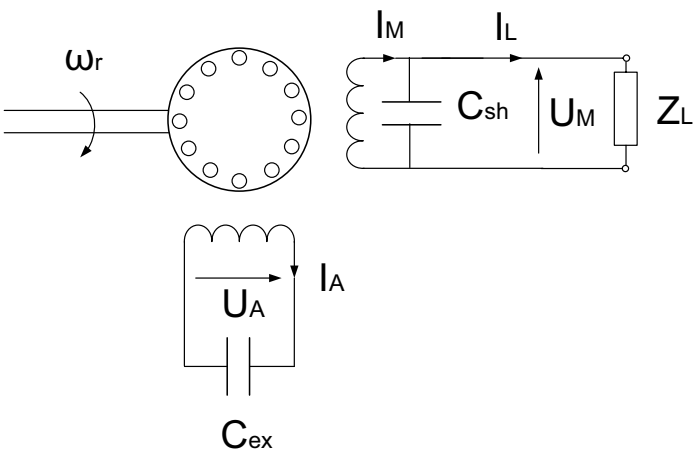

Fig. 4 Generator configuration with excitation and shunt capacitors

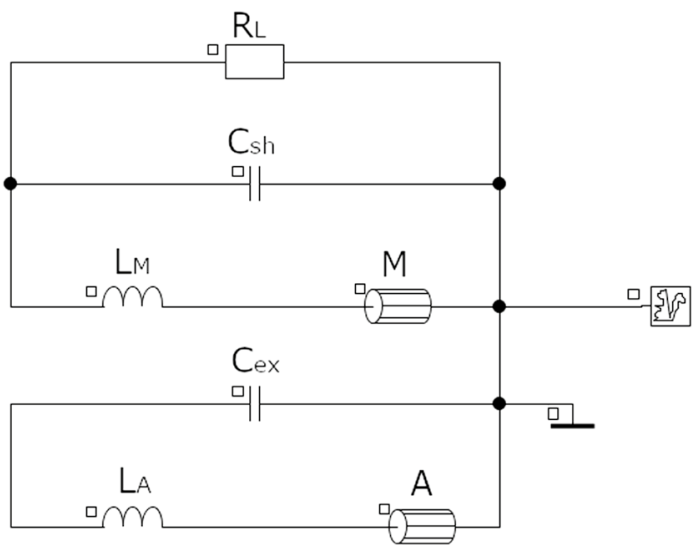

Fig. 5 Equivalent electrical circuit of the 2D field-circuit model of the single-phase induction generator

characteristic was approximated on the basis of no-load test of the induction machine. The block diagram of laboratory set-up for measuring output characteristics of the generator was described in the paper [3].

The generator configuration for excitation $(30 \mu \mathrm{F})$ and shunt $(15 \mu \mathrm{F})$ capacitors operating under resistive load has been analysed, of which electric circuit diagram is presented in Fig. 4. The capacitance values were selected to ensure self-excitation of the base generator at nominal speed-the machine with aluminium, rounded trapezoidal rotor bars, for rotor speed of $1620 \mathrm{rpm}$, excites to the rated voltage at noload. It was assumed for the analysis that the capacitances are constant. By connecting a shunt capacitor $C_{\mathrm{sh}}$ to the main stator winding, the self-excitation is partially shifted to that stator winding and thereby the auxiliary winding current of the generator may be reduced [3].

The stator windings of the generator are single-layer twophase copper windings: the main $(M)$ is the output winding of the generator (shown in red in Fig. 1) to which resistive load $\left(R_{\mathrm{L}}\right)$ is connected (Fig. 5), and the auxiliary winding $(A)$ (shown in green in Fig. 1) which is the excitation winding 
of the generator with parallel connected capacitor $C_{\mathrm{ex}}$ to provide reactive power necessary for self-excitation. The stator windings were modelled as stranded coil conductors. The elements denoted as $M$ and $A$ in Fig. 5 represent the parts of the main and auxiliary (excitation) stator windings, respectively, placed in slots of the magnetic core and include the flux linkage and the total resistance of each phase stator winding. The parameters $L_{\mathrm{M}}, L_{\mathrm{A}}$ denote end-connection leakage inductances of the main and auxiliary stator winding, respectively. The rotor squirrel cage of the generator is made of aluminium or copper bars short-circuited by endrings. In order to take the skin effect into account, rotor bars are modelled as solid conductors. The rotor end connections (end-rings) are represented by resistances and leakage reactances modelled as constant circuit elements in 2D field-circuit model. The shaft of the generator was assumed

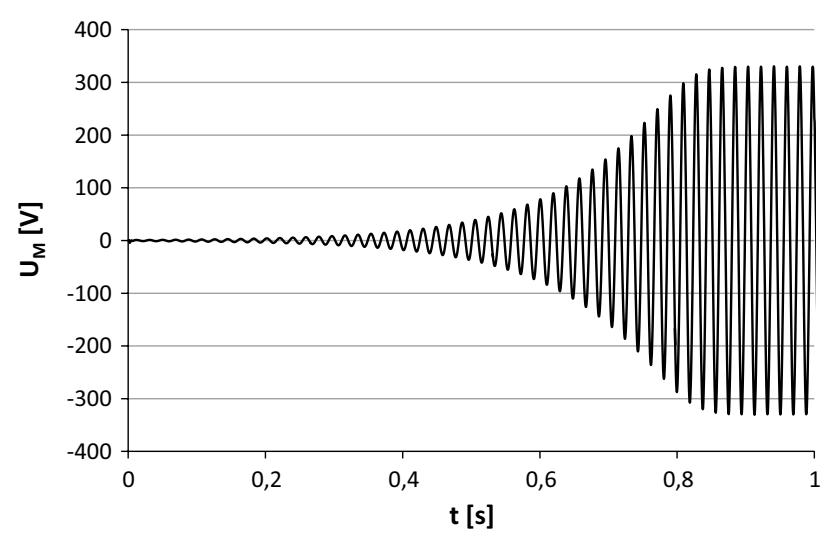

(a)

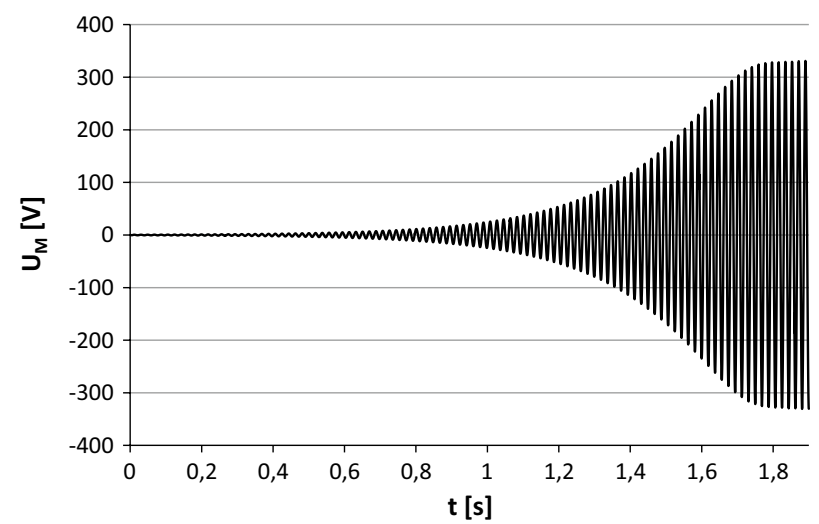

(b)

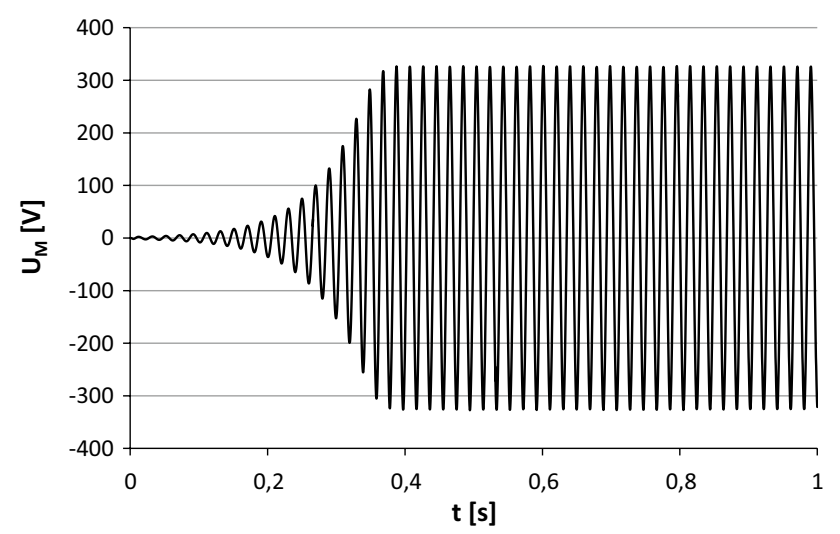

(c)

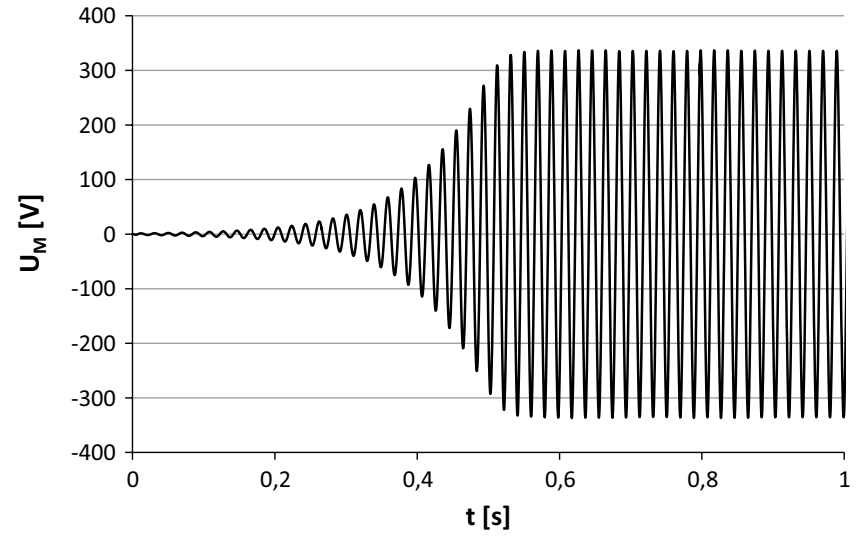

(d)

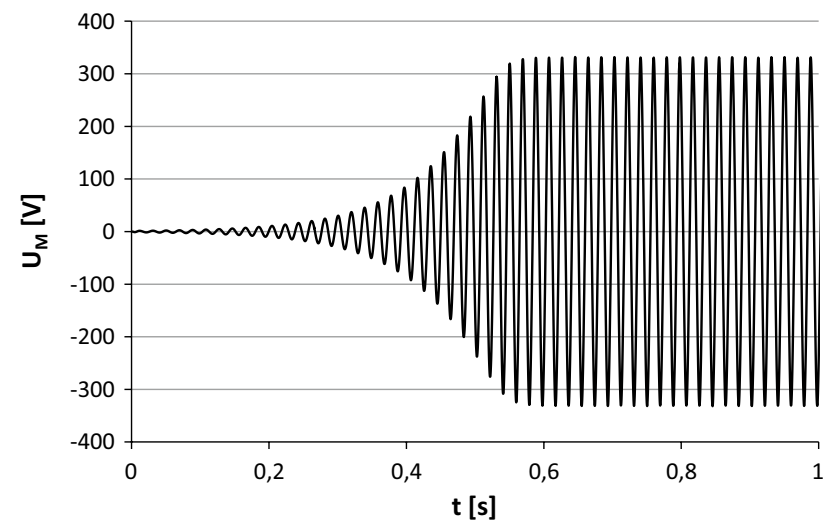

(e)

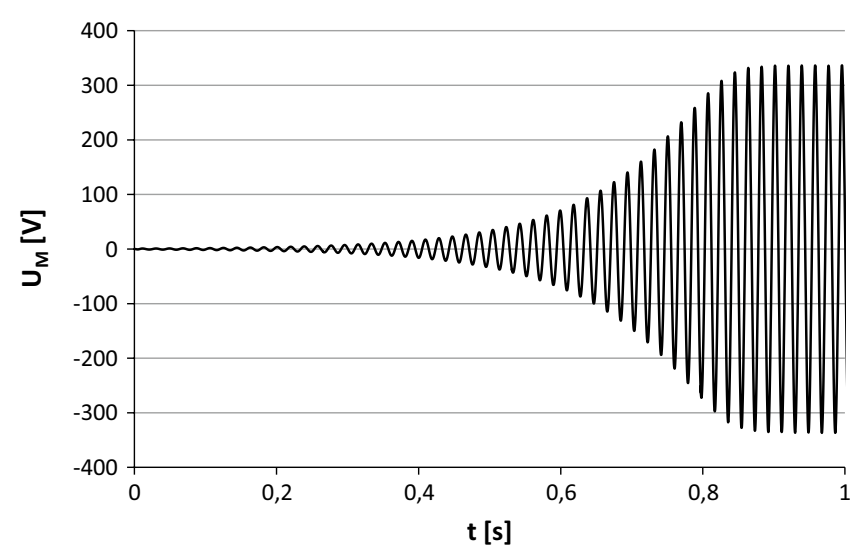

(f)

Fig. 6 Self-excitation waveforms of main stator winding for: a aluminium rounded trapezoidal bars, $\mathbf{b}$ copper rounded trapezoidal bars, $\mathbf{c}$ aluminium round bars, $\mathbf{d}$ copper round bars, $\mathbf{e}$ aluminium rectangular bars, $\mathbf{f}$ copper rectangular bars 


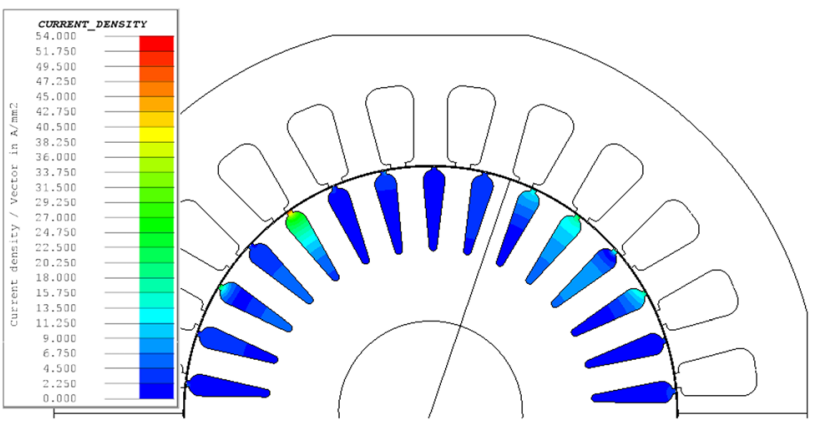

Fig. 7 Current density distribution in aluminium rounded trapezoidal rotor bars

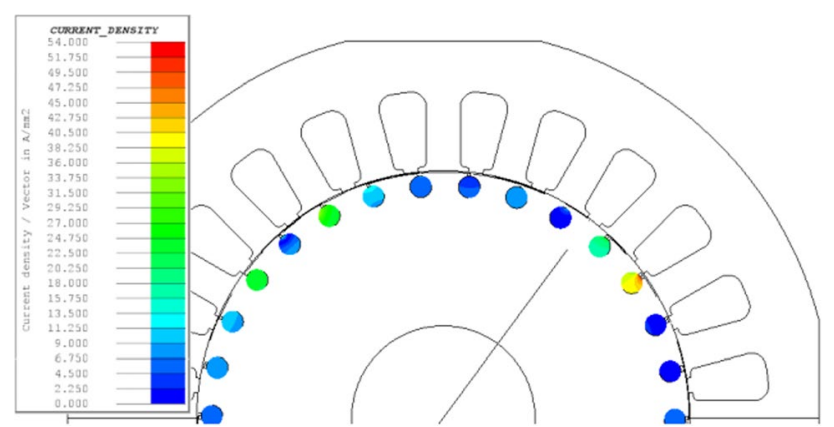

Fig. 8 Current density distribution in aluminium round rotor bars

to be non-magnetic, and homogenous Dirichlet boundary conditions were applied to its edge.

Waveforms of the main winding voltage during no-load self-excitation of the induction generator for the three shapes of the rotor bars (Fig. 2), made of aluminium (original) and copper, are presented in Fig. 6. It could be generally observed that, regardless of rotor bar shapes, self-excitation time of the generator for the copper cages is longer than for the aluminium ones, and the obtained values of self-excitation voltage of the generator are slightly higher. Since in the round rotor bars, skin effect practically does not take place, the shortest time $t=0.4 \mathrm{~s}$ was obtained for the aluminium round rotor bars, i.e. voltage build-up time is about $0.2 \mathrm{~s}$ shorter than for the rotor with round copper bars. Due to quite strong skin effect in rounded trapezoidal bars, time of self-excitation of the generator for the copper bars is going to be the longest. For the rotor cage made of rectangular bars, influence of the copper rotor bars on self-excitation process of the generator is similar to rounded trapezoidal bars but less visible due to less intensive skin effect.

Charts of current density distribution in rotor bars for copper and aluminium are shown in Figs. 7, 8, 9, 10, 11, and 12.

For validation of simulation results, some comparison of simulation load characteristics for the base model with

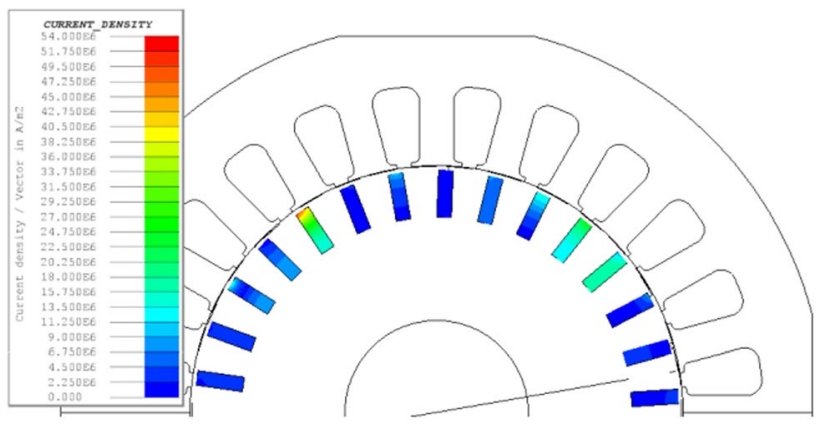

Fig. 9 Current density distribution in aluminium rectangular rotor bars

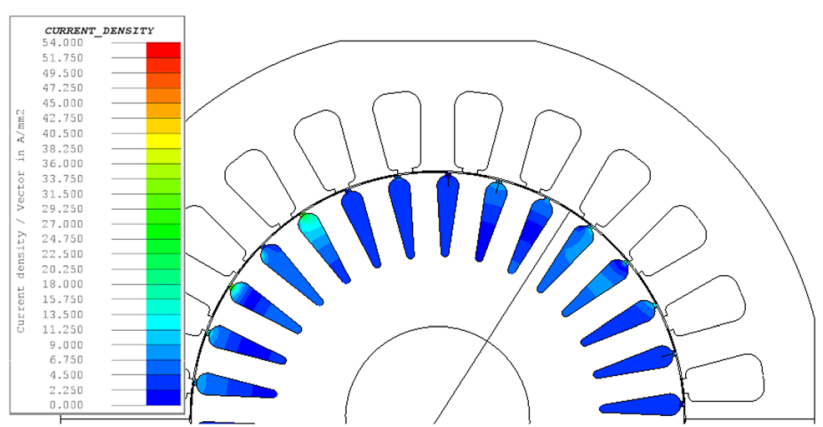

Fig. 10 Current density distribution in copper rounded trapezoidal rotor bars

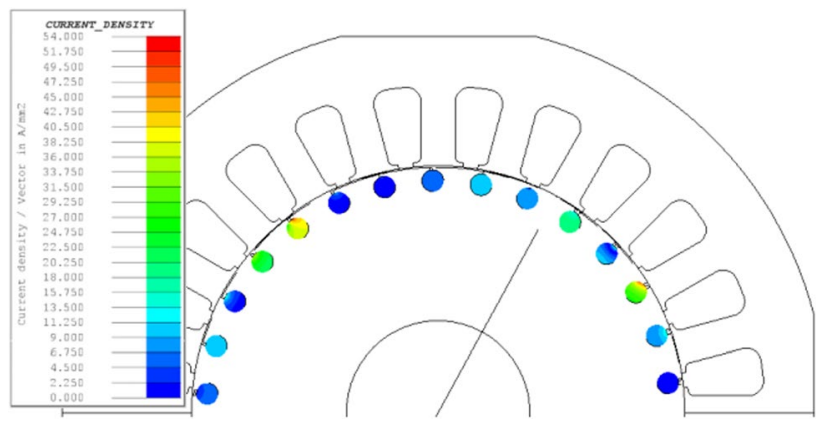

Fig. 11 Current density distribution in copper round rotor bars

corresponding experimental results were done only for aluminium rounded trapezoidal bars, which are presented in Fig. 13, where the measured terminal voltages are in enough good agreement with the computed voltages.

Load characteristics of the SP-SEIG for various shapes of rotor bars made of aluminium and copper are shown in Figs. 14, 15, 16, 17, 18, and 19. The carried-out computations revealed that the substitution of aluminium rotor bars by copper ones of the same shape has no considerable impact on regulation of the output voltage of the generator; 


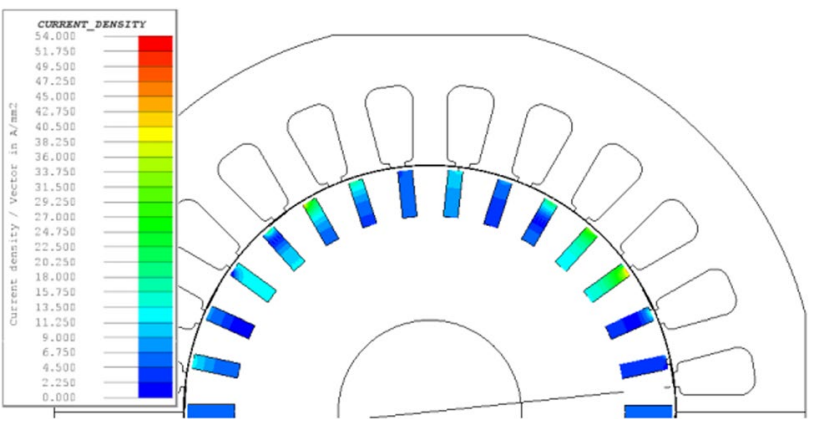

Fig. 12 Current density distribution in copper rectangular rotor bars

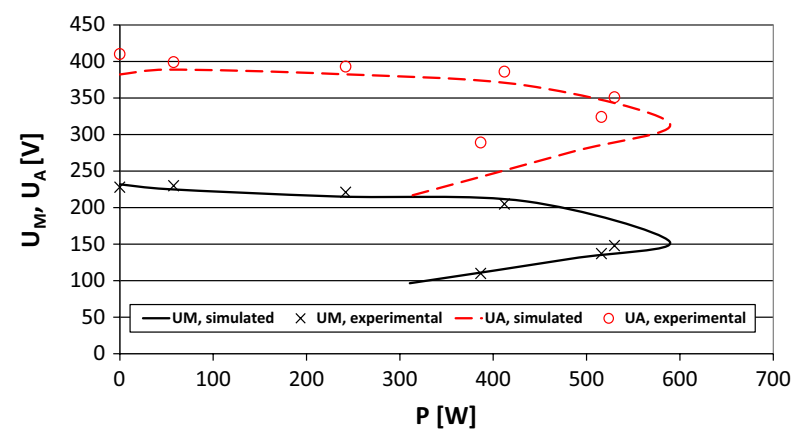

(a)

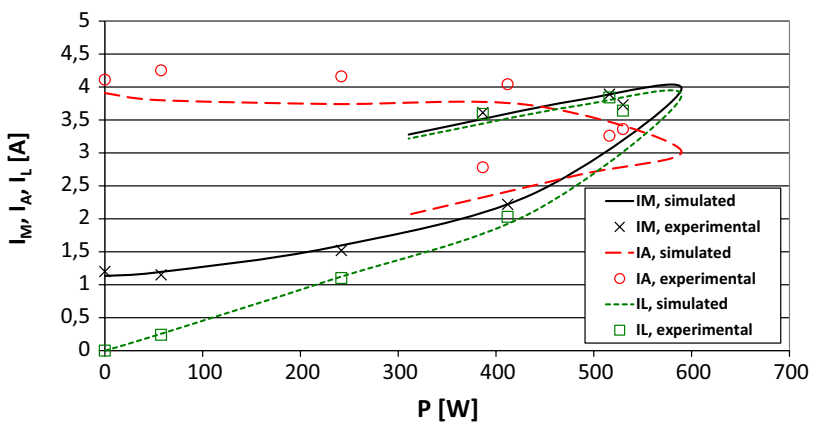

(b)

Fig. 13 Voltages (a) and currents (b) versus output power of the SPSEIG of aluminium rounded trapezoidal bars

however, when using copper rectangular rotor bars instead of aluminium ones, stronger skin effect and the associated increase in bar resistance allow for large output power of the generator and at the same time for increasing feeding load of the single-phase self-excited induction generator by about $15 \%$.

The output characteristics of SP-SEIG under inductive load for copper and aluminium rotor cages are shown in Figs. 20, 21, 22, and 23.

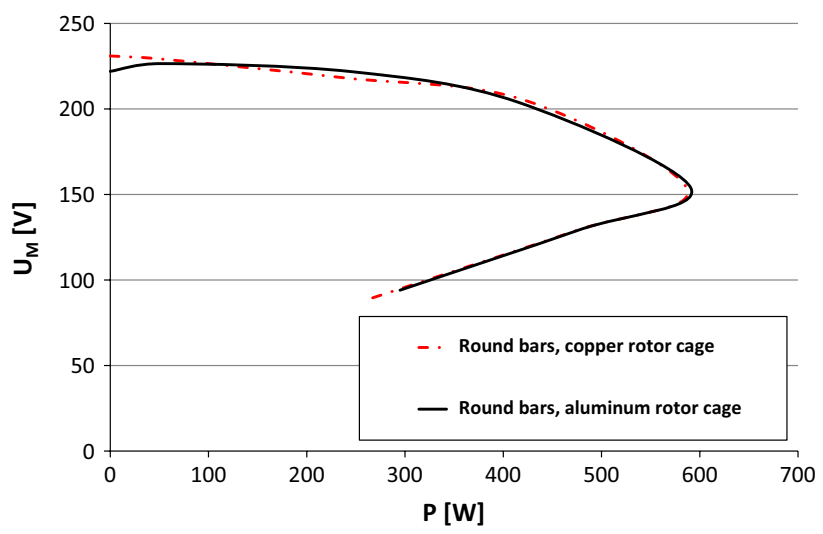

Fig. 14 Terminal voltage versus output power of the SP-SEIG for aluminium and copper round rotor bars

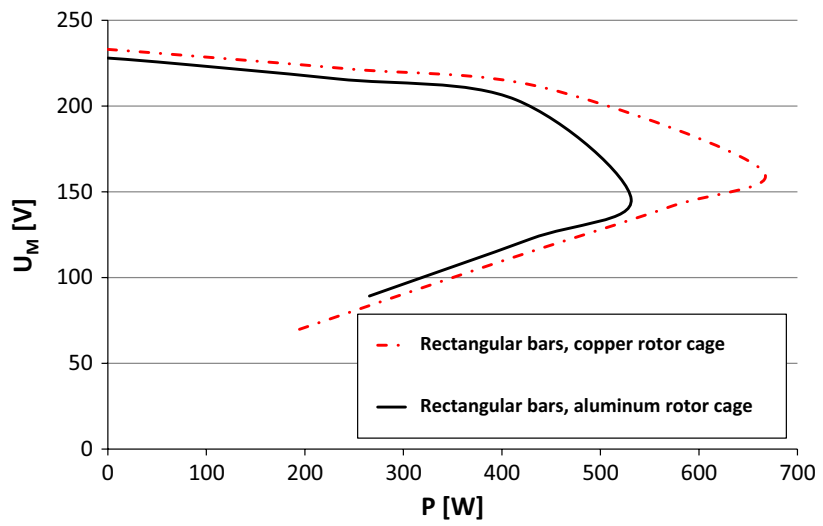

Fig. 15 Terminal voltage versus output power of the SP-SEIG for aluminium and copper rectangular rotor bars

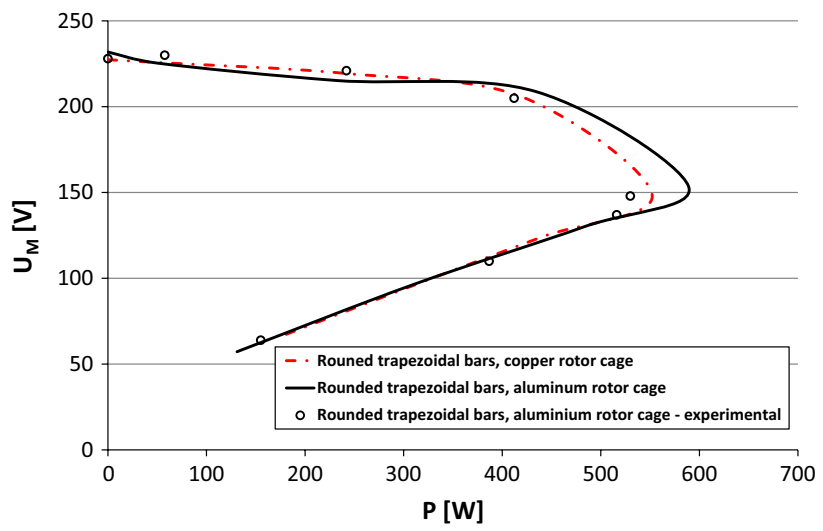

Fig. 16 Terminal voltage versus output power of the SP-SEIG for aluminium and copper rounded trapezoidal rotor bars 


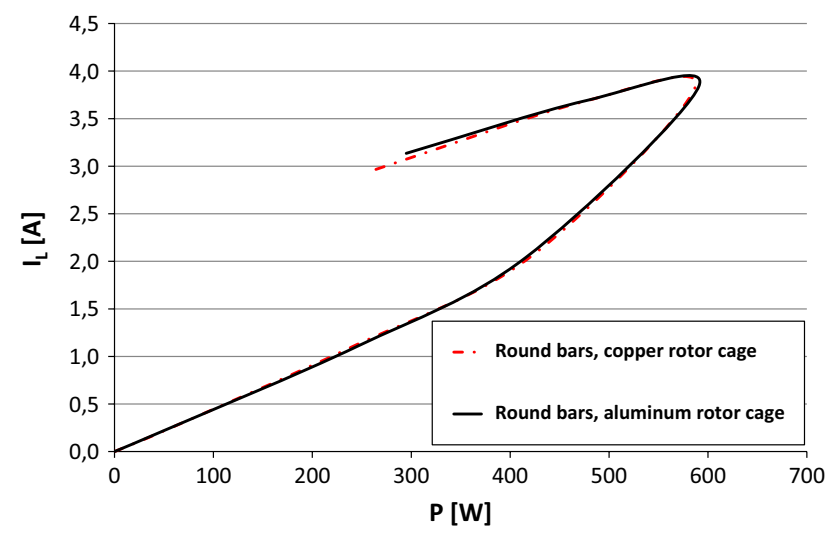

Fig. 17 Load current versus output power of the SP-SEIG for aluminium and copper round rotor bars

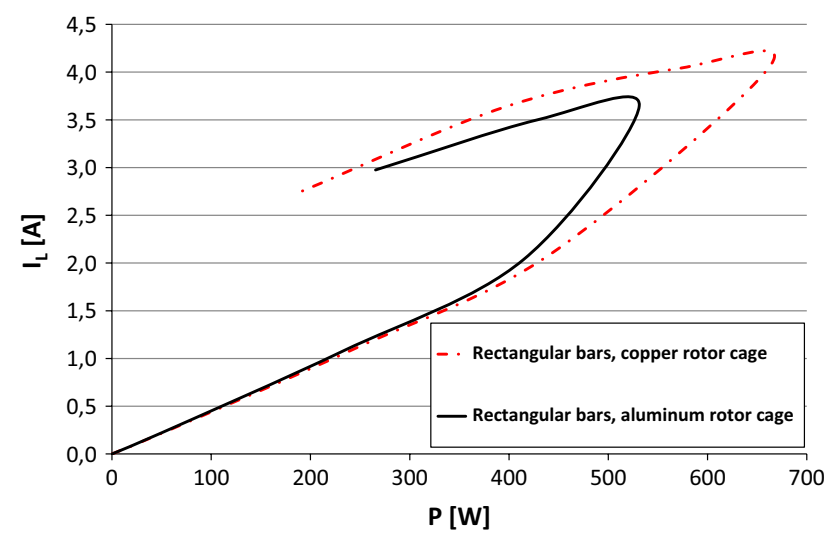

Fig. 18 Load current versus output power of the SP-SEIG for aluminium and copper rectangular rotor bars

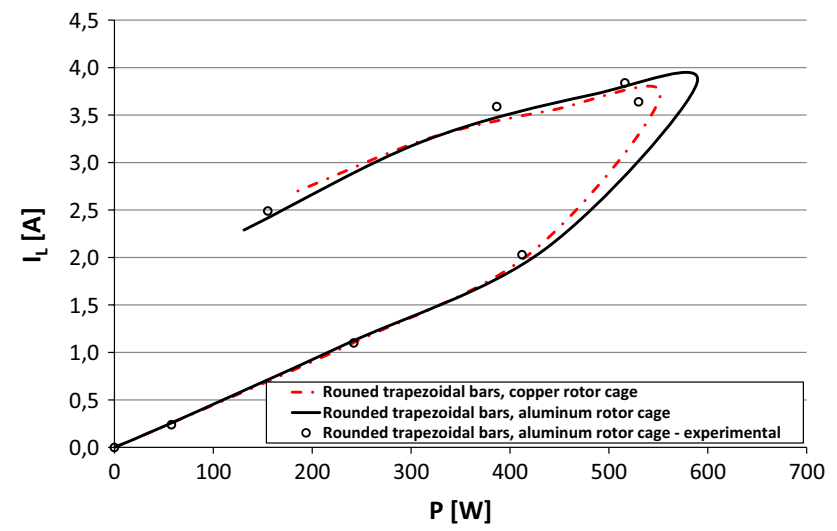

Fig. 19 Load current versus output power of the SP-SEIG for aluminium and copper rounded trapezoidal rotor bars

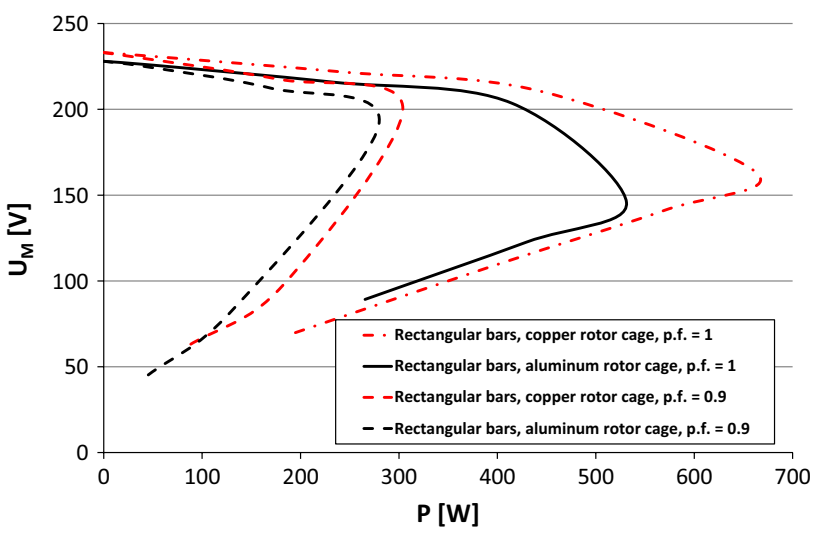

Fig. 20 Terminal voltage versus output power of the SP-SEIG for aluminium and copper rectangular rotor bars

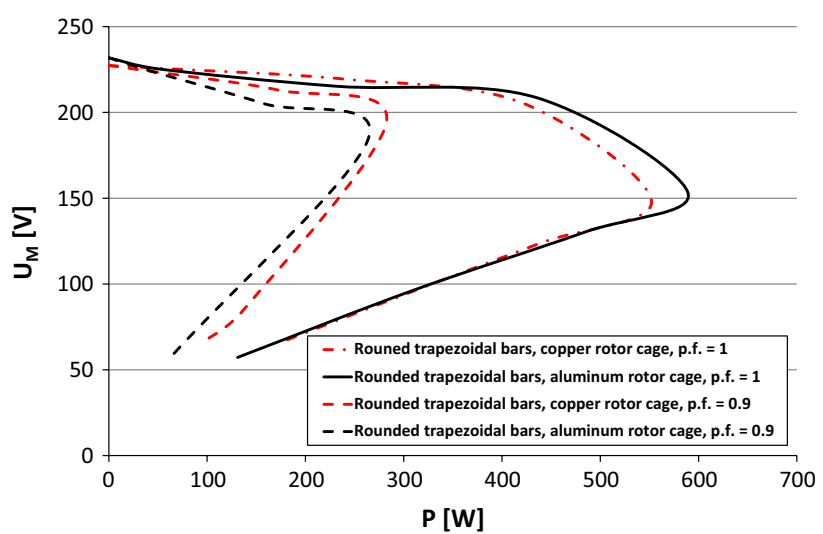

Fig. 21 Terminal voltage versus output power of the SP-SEIG for aluminium and copper rounded trapezoidal rotor bars

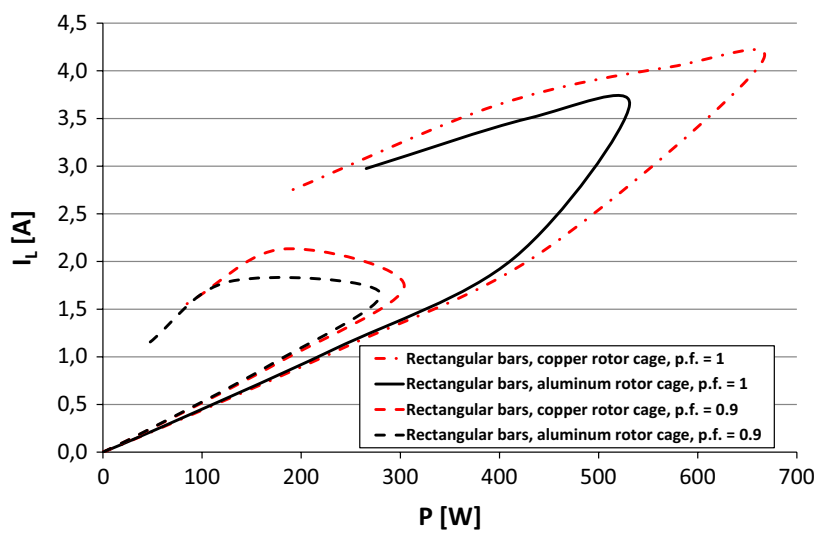

Fig. 22 Load current versus output power of the SP-SEIG for aluminium and copper rectangular rotor bars 


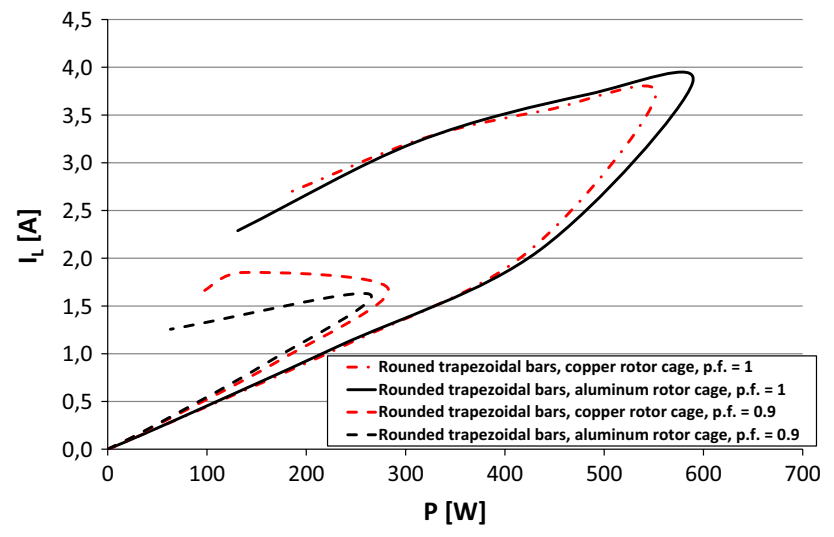

Fig. 23 Load current versus output power of the SP-SEIG for aluminium and copper rounded trapezoidal rotor bars

\section{Conclusions}

The copper and aluminium squirrel rotor cages with bars of three various shapes in a single-phase self-excited induction generator were investigated in the paper. The simulated self-excitation waveforms of terminal voltages, currents, as well as load characteristics of the single-phase induction generator feeding resistive load, were compared for two different conducting materials of the rotor cage. The obtained resultant characteristics of the generator showed that the application of copper rotor cages instead of aluminium ones lengthens twice in time self-excitation process in induction generator for rounded trapezoidal rotor bars and only by split second for the other bar shapes. The copper rotor bars have positive influence on stability of steady-state operation of the generator under resistive and inductive loads (Figs. 20, 22) as can be distinctly observed on the performance characteristics for rectangular rotor bars regardless of character of load. By employment of the simulation field-circuit model, an extension of the stable operating range of the SP-SEIG for copper rectangular rotor bars was obtained. As regards current density distribution in rotor bars, the current densities are almost the same for different shapes, except for rectangular rotor bars, where they are lower for copper rotor bars (Figs. 12, 18). Applying rectangular copper rotor bars, due to smaller damping of induced currents in the rotor cage, the widest stable steady-state operating range of the SP-SEIG may be obtained.

Open Access This article is distributed under the terms of the Creative Commons Attribution 4.0 International License (http://creativeco mmons.org/licenses/by/4.0/), which permits unrestricted use, distribution, and reproduction in any medium, provided you give appropriate credit to the original author(s) and the source, provide a link to the Creative Commons license, and indicate if changes were made.

\section{References}

1. Kalla UK, Singh B, Murthy SS, Jain C, Kant K (2018) Adaptive sliding mode control of standalone single-phase microgrid using hydro, wind, and solar PV array-based generation. IEEE Trans Smart Grid 9(6):6806-6814

2. Makowski K, Leicht A (2016) Analysis of self-excitation and performance characteristics of a single-phase self-excited induction generator by field-circuit method. COMPEL Int J Comput Math Electr Electron Eng 35(1):200-224

3. Makowski K, Leicht A (2017) Field-circuit analysis and measurements of a single-phase self-excited induction generator. Open Phys 15(1):913-917

4. Leicht A, Makowski K (2018) An influence of shape and material of rotor bars on performance characteristics of single-phase selfexcited induction generators. In: XXVth symposium on electromagnetic phenomena in nonlinear circuits (EPNC 2018), Arras, France, 26-29 June 2018, pp 1-2

5. Murthy SS, Singh B, Sandeep V (2013) Design-based computational procedure for performance prediction and analysis of single-phase self-excited induction generator. IET Electr Power Appl 7(6):477-486

6. Ojo O, Omozusi O, Jimoh AA (2000) The operation of an inverter-assisted single-phase induction generator. IEEE Trans Ind Electron 47(3):632-640

7. Benhacine TZE, Nesba A, Mekhtoub S, Ibtiouen R (2019) A new approach for steady state analysis of three-phase SEIG feeding single-phase load. COMPEL Int J Comput Math Electr Electron Eng 38(1):46-67

8. Shah M, Somkun S (2017) Efficiency evaluation of three phase and single phase $\mathrm{C} 2 \mathrm{C}$ self-excited induction generator for micro hydro power application. Energy Procedia 138:193-198

9. Zhong H, Wang B, Wu C, Wang J (2016) Performance analysis of three-phase self-excited induction generator under singlephase load. In: 2016 19th international conference on electrical machines and systems (ICEMS), pp 1-5

10. Boglietti A, Cavagnino A, Ferraris L, Lazzari M (2007) Energetic considerations about the use of cast copper squirrel cage induction motors. In: 33rd annual conference of the IEEE Industrial Electronics Society, IECON 2007, Taipei, pp 157-162

11. Finley WR, Hodowanec MM (2001) Selection of copper versus aluminum rotors for induction motors. IEEE Trans Ind Appl 37(6):1563-1573

12. Kirtley JL, Cowie JG, Brush EF, Peters DT, Kimmich R (2007) Improving induction motor efficiency with die-cast copper rotor cages. In: 2007 IEEE power engineering society general meeting, Tampa, FL, pp 1-6

13. Hafiz K, Nanda G, Kar NC (2010) Performance analysis of aluminum- and copper-rotor induction generators considering skin and thermal effects. IEEE Trans Ind Electron 57(1):181-192

14. Tudorache T, Melescu L, Petre V (2009) High efficiency squirrel cage induction machines. Renew Energy Power Quality J 1(7):239-244

Publisher's Note Springer Nature remains neutral with regard to jurisdictional claims in published maps and institutional affiliations. 